\title{
CAN LAST PLANNER ${ }^{\circledR}$ SYSTEM HELP TO OVERCOME THE NEGATIVE EFFECTS OF DESIGN-BID-BUILD?
}

\author{
Sergei Kortenko1, Lauri Koskela², Patricia Tzortzopoulos ${ }^{3}$, and Shervin \\ Haghsheno ${ }^{4}$
}

\begin{abstract}
The design-bid-build (DBB) procurement method has negative effects on construction projects. To find out whether those effects found in the literature appear in the field and to find ways to overcome them, nine interviews with practitioners from the architecture, engineering and construction industry have been conducted.

It was found that building a lean culture in the DBB projects and/or setting up a management system that acknowledges lean ideals can help to overcome the negative effects of DBB. Using compatibility assessments of teams and "add-ons" to the standard contracts such as FAC-1 (Framework Alliance Contract) or Construction Manager at Risk were also mentioned as ways to overcome the problems existing in DBB environment.

It was found from the interviews that Last Planner ${ }^{\circledR}$ System supports tackling the existing problems of DBB in number of ways. It enables building lean culture in the DBB projects through improving communication, visualization, transparency and collaboration, building trust, enhancing mood and relationships, as well as overcoming claim culture. It does help to minimize the negative effects of the DBB procurement method on construction projects.
\end{abstract}

\section{KEYWORDS}

Last Planner® System, design-bid-build, cost-led procurement, collaboration, action research.

\section{INTRODUCTION}

Kortenko et al. (2020) divided the direct and indirect negative effects of design-bid-build (DBB) procurement method on construction projects into two groups, "flow interruptions"

1 Researcher, School of Art, Design and Architecture, University of Huddersfield, Drees \& Sommer, Frankfurt am Main, Germany, +491727698610, sergei.kortenko@hud.ac.uk, kortenko86@gmail.com, orcid.org/0000-0003-0968-2100

2 Professor of Construction/Project Management, School of Art, Design and Architecture, University of Huddersfield, Queensgate, Huddersfield, HD1 3DH, UK, +441484472892, 1.koskela@ hud.ac.uk, orcid.org/0000-0003-4449-2281

3 Professor of Integrated Design, School of Art, Design and Architecture, University of Huddersfield, Queensgate, Huddersfield, HD1 3DH, UK, +441484472281, p.tzortzopoulos@hud.ac.uk, orcid.org/0000-0002-8740-6753

4 Professor, Karlsruhe Institute of Technology, Gotthard-Franz-Str. 3, 76131 Karlsruhe, Germany, +4972160842646, shervin.haghsheno@kit.edu, orcid.org/0000-0002-0602-6370

(B) The Lean Construction Institute (www.leanconstruction.org) holds a registered trademark on Last Planner® 
and "low margins". The underlying question motivating that research was whether Last Planner System (LPS) could help to fix those DBB problems.

The ability of LPS to mitigate DBB problems is not fully understood; the applicability of LPS in the DBB context has even been questioned. Matthews \& Howell (2005) see DBB as a constraint to the implementation of the Lean Project Delivery System. Dos Santos \& Tokede (2016) find that LPS may not be applicable to DBB. To gain deeper understanding in that area, interviews with nine practitioners from the architecture, engineering and construction (AEC) industry have been conducted. Main topics discussed were DBB and its effects on construction industry; the means of improving DBB projects; scheduling/planning; LPS in DBB environment and its ability to tackle DBB problems. The aim of this interview study is to understand: "Does $L P S$, if used in a DBB project, help to tackle the negative effects of the DBB environment?"

\section{METHOD}

When the nature of a phenomenon is not completely understood, Meredith (1998) suggests that answering questions of 'why' (understanding) around the topic is needed, instead of 'what' (identification) and 'how' (explanation). Interviews enable the researcher to explore unique participants' experiences (Meredith 1998) and to understand the meanings that they assign to various phenomena (Cooper \& Schindler 2008). To answer the research question, nine exploratory interviews with practitioners from the AEC industry have been conducted between $9^{\text {th }}$ and $20^{\text {th }}$ of November 2020 .

The interviewees were selected based on their overall experience in the AEC industry and their LPS experience. Each interviewee has both types of experience for 10 years or more. The aim was to cover different countries to avoid bias associated with local construction markets, their regulations and traditions. Therefore, interviews were conducted with practitioners from four counties: USA, UK, Germany, and Norway. Information about the interviewees is presented in Table 1.

Table 1: Interviewees: Party Represented and Current Position

\begin{tabular}{|c|c|c|}
\hline $\begin{array}{l}\text { Interviewee's } \\
\text { Code Number }\end{array}$ & $\begin{array}{l}\text { Party that Interviewee } \\
\text { Represents in the AEC Industry }\end{array}$ & $\begin{array}{l}\text { Interviewee's } \\
\text { Position }\end{array}$ \\
\hline 1 & General contractor & Development manager \\
\hline 2 & General contractor & Director of lean construction \\
\hline 3 & Client, General contractor & Lean construction consultant \\
\hline 4 & $\begin{array}{l}\text { Client, Designer, } \\
\text { General contractor }\end{array}$ & Consultant \\
\hline 5 & Client & Consultant \\
\hline 6 & Client & Consultant \\
\hline 7 & Academia & Professorial position \\
\hline 8 & General contractor & Consultant \\
\hline 9 & General contractor & Consultant \\
\hline
\end{tabular}

The interviewees were informed that their answers would be anonymized and used for academic purposes. They obtained a list with initial questions in advance. The planned length of the semi-structured interviews was 60-75 minutes, at the end it varied from 55 to 80 minutes, with one interview taking 125 minutes. All the interviews were organized 
and recorded via MS Teams. The recordings were transcribed verbatim. Only the research team has access to the recordings and transcripts. The transcripts were then categorized using MS Excel sheets.

The answers about the nature of DBB, its effects on construction industry and possible solutions to improve the DBB environment with lean thinking were then categorized into sub-topics, summarized and generalized. The preliminary findings from the manual analysis of these topics are presented below. Other topics discussed in the interviews are not included in this paper. Direct quotations are a basic source of raw data in qualitative research that reveals the informants' emotions, thoughts, experiences, and basic perceptions (Patton 2002). Direct quotations have been used to vividly transmit the respondents' views and opinions about using LPS in the DBB environment.

This study is a part of an ongoing $\mathrm{PhD}$ research. Action research (e.g., Iivari \& Venable 2009) is used as the overall research strategy for this study.

\section{LITERATURE REVIEW}

Kortenko et al. (2020) grouped the direct and indirect negative effects of the DBB procurement method on construction projects into two categories, "flow interruptions" and "low margins". These are both consequences and contributors to the following problems: fragmentation of the industry, poor constructability, lack of responsibility for the whole project, hindrance of learning, securing own contract, transferring risk, claims, short-term goals, change orders, silo thinking, lack of improvements, uncooperative behavior, opportunistic behavior, and lack of trust (ibid.).

Possible solutions to overcome the shortcomings of traditional procurement through novel forms of contract and organization have been widely discussed. Heidemann \& Gehbauer (2010) analyze advantages of the Integrated Form of Agreement in the USA and the Alliancing Agreement in Australia. Naoum (2003) describes positive impacts of Partnering on the UK construction projects. Cheng \& Johnson (2016) discuss successful implementation of the Integrated Project Delivery (IPD) in the USA and Canada. Even using some of the IPD principles improves performance in construction projects (Jenkins et al. 2020). However, sometimes it is not possible to use other forms of procurement than DBB: there are legal, cultural, behavioural, technological and financial barriers against implementing multi-party agreements (Dargham et al. 2019).

\section{FINDINGS}

The main findings from the interviews can be divided into three categories. First, the negative effects that DBB has on construction projects. Second, the ways of overcoming these effects in the DBB environment. Third, how can LPS, being used in the DBB environment, help to address these effects.

\section{NeGATIVE EFFECTS OF DBB}

DBB, by definition, means a separation of designers and contractors contractually and in time, at least partially, and is usually based on "the lowest bid wins" mentality. The effects of these DBB "features," as viewed by the interviewees, are presented below.

\section{Effects from the Contractual Separation}

Contractual separation of the companies involved in the construction process leads to managing of each company's risks separately. When risks occur, companies tend to try to shift their risks to the third parties. "Contractor is against designer, designer against 
owner, contractor against owner, and everyone against everyone... That leaves nobody out," as Interviewee 2 puts it. So, finally, all the companies in the construction project supply chain are pulled into a risk shifting mindset. Interviewees note that securing the contracts and shifting the risks are incentivized by DBB contracts. Interviewee 7 calls the relationships between an architect, an owner, and a contractor " a triangle of hate." Interviewee 6 argues that the companies cannot be blamed for this behavior "because that's the way the contract is set up. It's a mess." "There is risk shifting instead of risk management," as Interviewee 3 formulates. Every company involved in the construction process prices its risks. As Interviewee 6 states, "Risk is a commodity... People are trading risk in $D B B$. " The risk will manifest finally, but by that time the client will already have paid all the companies the contingencies that they have added to their contract prices to manage their risks. "If risk was managed collectively, there would still be insurance, but there would be one insurance policy, not 27, 53 or how many the number of delegations that have been through this system is, " Interviewee 5 explains. But that does not mean that somebody will deal with the problems occurred. At some point, according to Interviewee 5, "Risk is delegated to the level, below which it cannot be managed." If some company finally sees a risk, it is incentivized "to throw up your hands and say, "Not in contract, not in scope'," Interviewee 2 states and continues, "There's not even a requirement of when they need to tell you that they see a conflict in a field or in the documents. Typically, they just have to tell you if they notice it. Therefore, people tell you things are going wrong when it impacts them directly. But by then it's too late."

Contractual separation of the companies also leads to them having different goals. Absence of a common goal and companies' focus on their own parts of the project leads to "knowledge silos, meaning the borders, walls between different parties," as Interviewee 4 formulates. Not having a common goal, parties are optimizing their own parts due to the economic reasons. "And all that they're worried about is their own piece of the puzzle. Often at the expense of neighboring pieces of the puzzle, they maybe make decisions that suboptimize their piece, but actually are detrimental to the project overall. So, I think that that mentality can extend very easily down through those chains," as Interviewee 7 describes it. Interviewee 1 agrees with that, "You are more focused on your part and maybe lack the whole picture." "Every party has then its own monetary view on the construction project," Interviewee 4 states. Designers and contractors having different goals are set up for conflicts, Interviewee 3 gives an example of such a conflict, "As a designer, you need to manage your risks. You try not to be that explicit in your drawings, so that there's flexibility of later adjustments. But for a general contractor or a construction manager, it's important to have detailed drawings to minimize cost risks."

A shared understanding is often missing. This derives from the silos in which the parties are working and from a lack of the whole picture of the project. It creates conditions for rework. Interviewee 4 says that "the emphasis on the own targets of the different parties involved might be more difficult to integrate in DBB projects as you have more parties, more interfaces than you have in collaborative or integrated approaches." It also implies for a shared understanding of the interfaces, for example, between two trades on site. Interviewee 5 gives an example, "Without a shared understanding the workers who are executing a particular task have no guarantee that their work will be accepted when it's done. Because they don't know what the next team in line is, what the designer or the client wants from them. Yes, they've got something written down in a specification, but have they interpreted that specification in the same way that it was written? It's no guarantee that they would have done that." 
When asked about the atmosphere in DBB projects, its culture, environment in which people interact, interviewees often mention words with negative connotations such as "aggressive," "not pleasant," "untransparent," "not supporting," "not collaborative," "confrontational," "disrespectful," "protective," "not explicit." Further, people tend to "hide information" and "have hidden agenda." Interviewee 7 describes project participants" behavior in DBB environment as "self-preservation." This self-preservation leads to poor transparency, hidden information and, again, to unforeseen problems in the processes. Interviewee 2 links this behavior with the legal pressure because companies know that "lawsuits can entail, it makes people put the walls up and be very protective and keep information."

Interviewees express their concerns about missing collaboration and poor communication in the DBB environment. As Interviewee 2 formulates, "The word 'collaboration' never shows up in traditional DBB contracts, so why would people work together?" As Interviewee 6 states, "DBB contracts inhibit collaboration. They shouldn't, but they do." Interviewee 3 agrees, "There is a lot of waste in communication processes. It creates a certain tension in teams because everybody sees that the project isn't progressing that much or as it should, and everybody tries not being blamed for their work. So, they don't take risk, they don't share ideas. But instead, they try to shift work, shift risks to other participants and try to get their desk clean instead of solving the problem." Another issue that comes into play is the way the schedules are prepared. When a contract is signed, a schedule is usually a part of the contract. These schedules are normally prepared without collaboration with the contractors. Once a contract is signed, it is asked, "We have a plan, why do we need to get together?" as Interviewee 6 explains.

\section{Effects from the Separation in Time}

The fact that designers and contractors are separated in time, at least partially, means that contractors cannot be involved in the design process. It leads to several problems.

General contractor representatives argue that the decisions made by designers early in the process influence the buildability and cost-effectiveness. If some decisions have been made already, it is more difficult for the contractors to bring their know-how to the process, to use optimization, prefabrication, to use their knowledge and technologies to possibly accelerate the construction. As Interviewee 2 puts it, "The improvement in performance is not incentivized in the DBB contracts."

Because of poor constructability, there is rework in design. It, again, leads to blaming other parties, change orders, additional costs, and delays because usually one must have some iterations in all the design stages again to change something. By that point of time, however, the designers normally do not have budget left to make these changes. Here, again, the conflicts between the designers and contractors appear. Contractors want the designers to change or improve the design, designers want the contractors to take care of the designs themselves or just tell them to follow the existing decisions. Interviewee 1 describes some projects in the US construction market, "When it came to the detailed engineering part, my impression was that they had to do a lot of the detailed engineering once more, all over again because there were so many things they haven't thought of. And they lacked a feedback from the general contractor once he saw the drawings. And then they had to turn it all over and do it once more, a lot of it. That's counterproductive."

Additional work coming from the errors in drawings or specifications are big issues for contractors because clients typically do not see these tasks as an additional scope. These discussions about the scope might be very time- and money-consuming. 
Interviewee 1, a general contractor representative, estimates these discussions at tens of millions of euros for the company and adds that they "need to go to court with some clients because of this". Interviewee 8, another general contractor representative, adds that "you think about your own scope, you just want to do what is in your scope and nothing more, because if you do something more, you don't get paid for it". As Interviewee 2 states, "You do the minimum that's required ... and you protect yourself."

\section{Effects from the "Lowest Bid Wins" Mentality}

One of the ideas behind DBB is "the lowest bid wins". This, however, does not necessarily lead to minimizing the cost of the project. Interviewee 7 explains, "People don't realize some of the problems that are created ... by the siloed system of DBB. So, that initial number might be really good. The final cost, the ultimate cost ... is different."

Interviewee 2 describes a situation when an owner changes a design team after an initial programming phase to create design documents with an idea to minimize project costs and argues that it disrupts the process and increases the number of interpretations of the documents, drawings, specifications, requirements, "You can engage another set of people... to interpret those documents again. So, every time that they think they're doing things to save money, they are really just increasing their costs."

Interviewee 2 adds that choosing a contractor based on the lowest price does not consider the past record of the company and its qualifications and thus is not ensuring the future quality of the product.

Many interviewees find that DBB is encouraging claim culture. There are economic reasons for it as the companies' margins are low. Interviewee 9 finds that " $D B B$ encourages contractors and trade partners to overlook any gaps in the design so that they can change order for it later. If they're putting attention to it now, it will just make their cost higher and lessen their chances of getting hired."

\section{How Can The Negative EfFects of DBB Be Overcome?}

The interviewees were asked about the countermeasures to the problems created by the DBB structure: "If the integrated forms of procurement, multi-party agreements cannot be used, how can the existing problems within the DBB projects be overcome?" To understand why these procurement methods are not being used in particular cases is not a part of this study. We want to understand what can be done to address the potential problems if the use of DBB in a particular project has already been decided.

First, the interviewees suggest building a lean culture in the projects. It can be arranged by an owner. Principles, under which an owner is managing a project, might then influence the whole supply chain. It is recommended to set up a management system that appreciates alignment of the project goals, visualization of the work, collaboration between the participants, and use of the pull systems when planning the work. Many interviewees refer to strong leaders who can build such a culture, even if they do not call it "lean". These leaders can be on all sides: clients, designers, contractors, consultants.

Second, even in the DBB environment it is possible to use behavior and compatibility assessments before nominating companies for the project. The goal here is to build a highperformance team that will work collaboratively. Workshops with potential designers and contractors might be arranged. Obviously, it is difficult to do that without willingness from a client side, and the lowest bid should not be the sole criteria.

Third, the interviewees mention alternatives or "add-ons" to the traditional DBB contracts that allow engaging the contractors in the design process earlier. These are Framework Alliance Contract (FAC-1) and Construction Manager at Risk (CMAR). 
FAC-1 is a flexible meta-contractual model which regulates and manages the relations between different parties that are not directly associated over a contract (Di Giuda et al. 2020). In the CMAR delivery model, the owner still has separate contracts with construction manager and designer; construction manager is taking performance risk and responsibility by owning the trade contracts (Bilbo et al. 2014). Both models engage the contractors earlier in the design process.

From our point of view, LPS cannot help to overcome all the negative effects that DBB has on the construction environment, but it can help to create a project culture where some of these effects can be addressed and minimized. LPS enables and supports the first two suggested solutions to improve DBB environment and can be used with FAC-1 contract and CMAR procurement method. The interviewees support these ideas.

\section{How Does LPS SuPport BuILding A Lean Culture?}

It is clear from the interviews that LPS helps to solve some of the DBB problems. But is it LPS itself that solves that problems? Interviewee 4 states, "If you have a stable successful project, it doesn't matter, with lean or without lean. You will have a good atmosphere. And that's the only reason why people say, 'We had a great atmosphere.' No, you only had a great atmosphere because a project was running well, otherwise it would be the same as before." Interviewee 9 agrees with that, "It's not LPS itself that is influencing the atmosphere. LPS enables that to happen, but you could follow LPS and do really poor job. It's really the team leadership that matters. It can be a superintendent, it can be a project manager, it could even be one of the subcontractors, if they stand up, take the lead and say, 'Let's be intentional about this, let's behave this way,' that can foster that. But if you don't have anyone doing that, and if you don't have people focusing on reliable commitments, they're not focusing on the right conversations within LPS, then it won't matter." Therefore, when we say further, "LPS improves..." or "LPS influences...", it means that using LPS enables that to happen, but to be successful, projects will still need strong leaders, dedicated teams, experienced clients.

LPS improves communication. "It makes people talk," as Interviewee 2 puts it. LPS creates a forum where the information exchange takes place direct and efficiently. People are having conversations that would normally take them far more time, if they would have used phone calls, e-mails, or even direct face-to-face communication between two parties. Regardless of the contract, if people are given an opportunity to express in words and to put on a sheet of paper their thoughts that are visible to everybody involved in the process, it improves communication between these people. Interviewee 6 says, "You're asking people for their input. You are not pushing your program on them. It just turns on in their head, especially people who are new to it because they've never been involved in anything like this. They've never been asked what they needed, what they wanted."

Being together in the same physical space, where the LPS sessions take place, for example, a big room, creates transparency. Interviewee 1 explains, "Being physically close to each other, sitting close to each other in the same office for some days a week, is the best solution. Because there are so many details in construction projects, there are so many clarifications you need. And also, it's easier to develop some sort of trust. When you see a person face-to-face, it is harder to make a promise you know you can't fulfil than when you give it on phone or by e-mail."

The design and construction processes are being visualized by LPS. Visualization reduces complexity. It is beneficial for all the parties involved in the process to see what 
will happen next to them in that process. Pull planning and make-ready process create shared understanding and show a common goal, e. g. the next milestone in the process.

Interviewee 2 claims that "the team changes the complexity of the project. Our plan depends on the contractors and their capability, experience, labor availability. There are so many factors." It means that those involved in a construction project have to act as a team and acknowledge all its members. LPS does that through creating a plan with the very people who are working in a project. Interviewee 5 underlines the social processes behind the LPS, "What I've been trying to do throughout is get people to understand that construction is a social process. We need to use really solid social processes, particularly the promise cycle to manage the way the work works. And we want you to be in a really sound position, when you're called on to make promises. We're not going to ask you to make promises until a week or so, maybe less, before the work is due to be done."

When asked about their input, participants tend to feel involved in the planning process and are eager to contribute. LPS improves the reliability of the promises and thus helps to build trust between the participants. Interviewee 5 describes it, "LPS provides levels of information that makes it easier to trust. The promise cycle is the basis for building trust." "It helps people build stronger relationships," Interviewee 9 explains and continues, "It helps enhance, I guess, your feeling of relationship, friendship, bonding. And it influences how you are interacting in another meeting, how you are interacting in the field. You start actually care about each other. All that soft things that we never bother to pay attention to in construction." Interviewee 4 adds, "People are curious. People are interested, they want to know what this is, they want to learn and to explore it, they want to find out if that can also work for them."

When asked about the atmosphere in the LPS sessions, interviewees use words with positive connotations: "open," "transparent," "motivating," "positive," "energetic." LPS also improves the mood of participants, builds a team. It comes with conversations, shared understanding, building trust, improved reliability, making commitments. Leaders should start behaving differently, the others will then be pulled into new collaborative environment. Interviewee 5 says, "Managing moods is really important for leadership on projects. If the mood is right, then people are learning. If the mood is wrong, people stop learning." Interviewee 3 describes this open and transparent environment, "It's an atmosphere where everybody can speak about assumptions, risks, and ideas. Nobody needs to present perfect solutions. We're very fine with communicating the possibilities instead of solutions. "It means that risks are being discussed and managed collaboratively.

How does a good LPS session look like? For Interviewee 2, "It should be noisy, people should be talking to each other, people should be told to shut up because they're getting too noisy... Those conversations are happening with a lot of activity. If you're in the back of the room filming it, you just see like a flurry of people moving to the board, away from the board, back, having side conversations, negotiating, changing information. It needs to be messy. I think the family dinner is probably the best analogy. If it's not going well, it's going to look like a library." For Interviewee 5, "The meetings need to be crisp, courteous and very much to the point. It's very easy to get lost in taking too much time over it, but it's about learning how to go through the process quite quickly."

Interviewees find that LPS helps to overcome a claim culture in construction. People have an opportunity of raising hand and talking about the possible hindrances in advance. Moreover, during the pull planning process, the companies name their prerequisites, during the make-ready process they are removing constraints together. Interviewee 5 describes it, "I do think that LPS discourages claim culture in that it gives the companies 
the chance to buy in to the plan. After they are bought in to it, if they've been a part of the creation of it, making claims against it now is almost to claim against yourself and your own involvement." Interviewee 5 adds, "LPS helps to overcome claim culture, because the documentation is really clear, and everyone's got access to the data. So, it should be a lot easier to keep the project on time which reduces the risk of a claim." However, Interviewee 4 separates between claims due to hindrances which may decrease and claims due to design changes and process changes. The latter ones will not be influenced by LPS: "How can you avoid them if the client wants to change something and she or he has the power to do so? But what you can do is you can mitigate design changes if you can manage to identify the customer value properly. And of course, LPS will not help you in that. Because LPS is a methodology for managing the schedule. Not for managing cost and not for managing the quality. Of course, if you have a proper schedule, you will have a passive impact on the cost and the passive effect on the quality, but not an active one."

\section{DISCUSSION}

LPS does not solve all the negative effects created and supported by DBB because some of them are programmed, they are in the nature of DBB. LPS cannot tackle these attributes of $\mathrm{DBB}$, but it helps to minimize some negative effects.

For instance, if FAC-1 (or a similar scheme) is not being used, designers and contractors will be separated contractually. Thus, the companies will still be managing their contracts and risks separately. However, LPS creates a forum where the common risks can be identified beforehand and therefore can be managed more efficiently. In phase pull planning and look-ahead planning, risks are being made visible and can be discussed between all the parties involved in a particular project phase.

Even if LPS is used in all stages of a project, the designers will still be separated from the contractors in time, if FAC-1 or CMAR are not being used. It means that the contractors will not bring their input into design decisions, therefore, a tension between the designers and contractors might still be there. However, during the look-ahead process in the construction phase, the input needed from the designers can be structured, scheduled and justified by the work sequence in the construction phase, which can support the flow in producing the drawings needed on the construction site.

Using LPS will also not ensure qualifications of the companies involved in the project delivery. However, LPS can help to reveal how a potential team will work together if used in separate workshops before nominating the contracts.

It is important to emphasize that LPS itself does not necessarily help to improve DBB project environment, but creates prerequisites for such an improvement. LPS can be seen as an enabler, as a tool that can help the leaders to create a collaborative culture and to organize their cooperation with the companies involved in a construction project. If used with traditional mindset, without understanding of lean ideals, LPS can become a cargo cult in hands of those believing that just having sticky notes on a board will help them to avoid the traditional project problems and bring them to a project success. It will not.

\section{CONCLUSIONS}

Nine interviews with LPS practitioners from the AEC industry have been conducted. The interviewees support the literature findings that DBB has negative effects on construction projects. The interviewees name several ways of improving DBB contracts, such as building a lean culture in a project and/or setting up a management system that 
acknowledges lean ideals, using assessments of the teams, using "add-ons" to the DBB contracts, such as FAC-1 or CMAR. LPS cannot help to overcome all the problems created by DBB, but it can support the ways of improving DBB suggested by the interviewees. LPS enables building lean culture in the DBB projects through improving communication, visualization, transparency, collaboration, building trust, enhancing mood and relationships, and overcoming claim culture. It therefore does help to minimize the negative effects of DBB procurement on construction projects.

\section{REFERENCES}

Bilbo, D., Bigelow, B., Escamilla, E. \& Lockwood, C. (2014). "Comparison of Construction Manager at Risk and Integrated Project Delivery Performance on Healthcare Projects: A Comparative Case Study." Int. J. Construct. Educ. Res., 11(1), 40-53.

Cheng, R. \& Johnson, A. (2016). Motivation and Means: How and Why IPD and Lean Lead to Success. Minneapolis: Lean Construction Institute and Integrated Project Delivery Alliance. Accessed March 30, 2021. https://hdl.handle.net/11299/198897.

Cooper, C. R. \& Schindler, P. S. (2008). Business Research Methods, McGraw-Hill, Boston, USA.

Dargham, S. A., Hatoum, M. B., Tohme, M. \& Hamzeh, F. (2019). "Implementation of Integrated Project Delivery in Lebanon: Overcoming the Challenges." Proc. of the 27th Ann. Conf. of the Int'l Group for Lean Construction. Dublin, Ireland, 917-928.

Di Giuda, G. M., Giana, P. E., Schievano, M. \& Paleari, F. (2020). A Collaborative Approach for AEC Industry Digital Transformation: A Case Study, The School of Liscate. In: Della Torre, S., Bocciarelli, M., Daglio, L. \& Neri, R., eds. (2020). Buildings for Education: A Multidisciplinary Overview of The Design of School Buildings. Cham: Springer, 175-184.

Dos Santos, G. F. \& Tokede O. O. (2016). "Last Planner System-From Theory to Implementation." Proc. of the 10th Cost Engineering, Quantity Surveying \& Project Management World Congress. Rio De Janeiro, Brazil, 305-318.

Heidemann, A. \& Gehbauer, F. (2010). "Cooperative Project Delivery in an Environment of Strict Design-Bid-Build Tender Regulations." Proc. of the 18th Ann. Conf. of the Int'l Group for Lean Construction. Haifa, Israel, 581-587.

Iivari, J. \& Venable, J. (2009). "Action Research and Design Science Research Seemingly Similar but Decisively Dissimilar." ECIS 2009 Proceedings, 73.

Jenkins, G., Smith, J. P., Bingham, E. \& Weidman, J. (2020). "Application of Integrated Project Delivery Practices in Residential Construction." Proc. of the 28th Ann. Conf. of the Int'l Group for Lean Construction. Berkeley, California, 769-781.

Kortenko, S., Koskela, L., Tzortzopoulos, P. \& Haghsheno, S. (2020), "Negative Effects of Design-Bid-Build Procurement on Construction Projects." Proc. of the 28th Ann. Conf. of the Int'l Group for Lean Construction. Berkeley, California, USA, 733-744.

Matthews, O. \& Howell, G. A. (2005). "Integrated Project Delivery An Example of Relational Contracting." Lean Construct. J., 2(1), 46-61.

Meredith, J. (1998). "Building Operations Management Theory through Case and Field Research.” J. Oper. Manage., 16, 441-454.

Naoum, S. (2003). "An Overview into the Concept of Partnering." Int. J. Project Manage., 21(1), 71-76.

Patton, M. Q. (2002). Qualitative Research \& Evaluation Methods, Sage Publications, Thousand Oaks, California, USA. 